\title{
Cartografías Sociales: lenguaje y territorio. Una aproximación desde La Intervención en lo Social ${ }^{1}$
}

\author{
Alfredo J. M. Carballeda ${ }^{2}$
}

RESUMEN

\begin{abstract}
La creciente complejidad de los actuales escenarios sociales muestra la necesidad de desarrollar más y nuevas formas instrumentales de producción de conocimiento y transformación que aporten diferentes aproximaciones a la comprensión y explicación de lo social, y que a su vez, puedan ser útiles para el desarrollo de estrategias orientadas a la intervención en este campo. En este aspecto, las Cartografías Sociales ${ }^{3}$, se presentan como un hacer, una práctica, que surge o dialoga de forma estrecha desde y con los interrogantes que generan las diferentes expresiones actuales de la cuestión social, especialmente desde su inscripción en lo territorial, lo que le confiere más y nuevas posibilidades de conocer y transformar.
\end{abstract}

Palabras clave: Cartografías sociales, intervención social, trabajo social, territorios.

Cartografia social: linguagem e território. Uma abordagem desde a Intervenção no Social

RESUMO

A crescente complexidade dos cenários sociais atuais mostra a necessidade de desenvolver mais e novas formas instrumentais de produção de conhecimento e transformação que aportem diferentes abordagens para a compreensão e explicação do social e, por sua vez, possam ser úteis para o desenvolvimento de estratégias orientadas para a intervenção neste campo. A este respeito, as Cartografias Sociais são apresentadas como uma prática, uma prática que surge ou dialoga estreitamente desde e com as questões geradas pelas diferentes expressões da questão social, especialmente desde sua inscrição no territorial, o que lhe outorga mais e novas possibilidades de conhecer e transformar.

1 Colaboración solicitada al autor por la revista Perspectivas.

2 Argentino, Trabajador Social, Académico e investigador, Universidad Nacional de La Plata y Universidad de Buenos Aires, e-mail: alfredocarballeda@gmail.com

3 Se entiende la cartografía social "como una metodología participativa y colaborativa de investigación que invita a la reflexión, organización y acción alrededor de un espacio físico y social específico" (Vélez, Rátiva, Varela, 2012, p. 62). 
Cartografías Sociales: lenguaje y territorio. Una aproximación desde la Intervención en lo Social / Carballeda

Palavras-chave: Cartografias sociais, intervenção social, trabalho social, territórios.

Social Cartographies: Language and territory. An approach from the social intervention

ABSTRACT

The growing complexity of current social scenarios shows the need to create more and new instrumental forms of knowledge production and transformation that bring different approaches to the understanding and explanation of the social issue and which, in turn, can be useful for developing strategies oriented to interventions in this field. In this respect, Social Cartographies are presented as a doing, a practice that arises or dialogues narrowly from and with the questions generated by the different expressions of the social subject, especially since its registration in the territorial, with more and new possibilities of knowing and transforming.

Keywords: Social cartographies, social intervention, social work, territories.

\section{Introducción}

A partir de su capacidad de integrar lo teórico y lo instrumental, las cartografías sociales tienen la posibilidad de transformarse en un camino que facilite la constitución de un modo de acceso a diferentes formas de saber, donde lo singular, al estar situado en un espacio definido, se expresa cobrando forma de nuevas significaciones. Estas, al ser reconocidas y reinterpretadas pueden convertirse en otras formas de lenguaje que, tal vez, permitan profundizar, complejizar y poner en cuestión lo aceptado como natural, lo conocido, lo trasmitido, generando un camino de apropiación crítica y re significación de lo dado. Por otra parte, esta forma de construcción de conocimiento propone generar, de manera sistemática y organizada, desde la relación que se construye entre los actores sociales y el territorio, nuevas maneras de interpelación, mostrando también, muchas veces, la capacidad de responder a los interrogantes que surgen de ellas en forma situada. Es decir, a partir de una construcción que se desarrolla en un contexto que le imprime su singular influencia, intentando articular lo espacial con lo histórico social. De esta forma, es posible pensar a la Cartografía Social como una metodología que facilita la expresión co- 
lectiva e histórica que logra relatarse desde el territorio, desde un orden que surge de éste, o sea, de quienes lo habitan, lo construyen y son construidos en él. Logrando así, proponer una forma de lenguaje que tiene la posibilidad de decir, reflexionar y pasar a la acción desde diferentes perspectivas, visiones y posicionamientos, tanto históricos como sociales.

\section{Discusión}

Desde la construcción colectiva de un lenguaje, las Cartografías Sociales relatan historias donde, quizás, la veracidad dialoga y hace síntesis con la representación que se hacen de ellas quienes las cuentan. Las Cartografías Sociales no buscan, desde esta perspectiva, únicamente la exactitud del dato como en un mapa clásico, sino que también, tienen la posibilidad de acceder a conocer el impacto del mismo en la singularidad de lo histórico y lo colectivo,

Así, la Cartografía Social tiene la posibilidad de construir un lenguaje que implica también una modalidad de conocer, que facilita la producción de diferentes saberes acerca de aquello que construye nuevas preguntas y posibilidades de acción apoyadas en lo territorial, lo intersubjetivo y las diferentes formas de reciprocidad e intercambio, que pueden llevar a procesos de construcción de identidad y pertenencia. En definitiva, facilitando y construyendo otras modalidades de sociabilidad, de encuentro, donde los lazos sociales pueden ser edificados desde distintas perspectivas que se resignifican en la práctica. Pero también, esa forma de construcción de conocimiento implica una nueva, y tal vez, más profunda modalidad de apropiación colectiva del espacio. Esta se facilita a través de la generación de formas de intervención social que lo atraviesan, pudiendo transformarlo, inscribiéndose en éste de manera simbólica y real. De este modo, a través de formas de relación heterogéneas que facilitan los procesos de intervención social se hace posible la elaboración y comprensión de significados generales y subjetivos fortaleciendo las interacciones que pueden aportar más y nuevas formas en la definición colectiva de la identidad. 
En este aspecto, se hace posible pensar la utilización de las Cartografías Sociales como una intervención que va mucho más allá de la descripción o aproximación a los espacios habitados, implicando también una posibilidad de apropiación y transformación de dichos espacios, cimentando a su vez, formas de comprensión y explicación de lo que ocurre, desde la lógica de quienes los habitan, generando acontecimiento, es decir, la reelaboración de los atravesamientos históricos, políticos y sociales.

Allí, la noción de acontecimiento se construye desde la conjugación de hechos y circunstancias que se hacen singulares en la explicación de aquello que está ocurriendo y cuyas causas y consecuencias tienen una expresión objetiva y subjetiva relevante. Las Cartografías como una forma de Intervención en lo Social, tienen la capacidad de trabajar desde la aplicación de las distintas formas de procesamiento y sistematización de la información que, muchas veces, al salirse de la formalidad del dato empírico intentando ir más allá de éste, construyen otras prioridades y formas de resolución de problemas en espacios de interacción desde lo colectivo.

Así, las Cartografías Sociales pueden ser entendidas como la posibilidad de construcción de una gramática, de un orden del discurso singular, de un lenguaje territorial, donde los que participan de ésta pueden elaborar, desde lo heterogéneo, visiones compartidas. Pautando, de esta manera, diferentes prioridades, jerarquías o inquietudes en los que se visibilizarían los temas, problemas o cuestiones que interpelan la cotidianidad y la atribución de sentidos en esa esfera; pudiendo, a su vez, tal vez lograr articular lo macrosocial y lo microsocial en la singularidad del territorio.

Por otra parte, esta modalidad de intervención puede hacer perceptible aquello que pasa desapercibido, que, a veces, por cotidiano y repetitivo desaparece del reconocimiento o de la inscripción subjetiva, sencillamente, a partir de la ubicación y reinscripción en el espacio de diferentes miradas que se complementan y muestran la capacidad de potenciarse. Reafirmando así la posibilidad 
de hacer ver, de ver con otros, desde otros a partir de la propia singularidad.

El manejo del lenguaje gráfico y el sentido colectivo del ejercicio cartográfico permite complementar nociones y construir encuentros frente a una realidad vivida y una realidad deseada. Desde la Cartografía Social se facilita la posibilidad de pensar que los espacios sociales, los lugares, no son estáticos, están en permanente proceso de construcción y deconstrucción objetiva y subjetiva; el hecho de que sean narrados, visibilizados e interpretados los hace inestables, con un movimiento permanente que requiere muchas veces ser asimilado y estudiado en forma de proceso histórico y social y no solo analizando la visión suspendida de éstos.

Lo territorial al inscribirse en los imaginarios sociales, les da forma y sentido para introducirse en la subjetividad de quienes los habitan o los visibilizan desde diferentes perspectivas y estrategias de comprensión de la realidad social. En el proceso de construcción de cartografías, también se hace posible develar las significaciones a través de las diferentes interacciones producidas durante ese proceso de elaboración de mapas que implica una revisión crítica del territorio. De allí, surge la necesidad de herramientas de conocimiento e Intervención Social que se adecuen a esas características, que logren construir y develar diferentes formas de intersección entre lo imaginario, lo real, la construcción de subjetividad y la visión de lo Otro, donde lo territorial implica la suma y construcción de un sentido como significado a un espacio, un lugar, cuya definición es validada por una comunidad.

Si los territorios son una construcción social que se define y redefine continuamente a partir de las significaciones y usos que sus pobladores construyen cotidianamente, gracias a historias comunes, usos y sentidos, las Cartografías Sociales se presentan como una forma de acceso a esa serie de cuestiones. En otras palabras, como un instrumento que tal vez permita conocer, a través no solo de la descripción de las partes de un todo definido como te- 
Cartografías Sociales: lenguaje y territorio. Una aproximación desde la Intervención en lo Social / Carballeda

rritorio, sino a partir de las formas de interacción, las relaciones y reciprocidades entre los componentes de éste.

El hacer mapas en forma colectiva y orientada a objetivos definidos es una forma de dibujar, de reinterpretar y develar lo real desde lo simple, para ir creando un campo de relaciones e intenciones cada vez más complejo que se traduce en la construcción de consensos y disensos para proyectar en conjunto. Desde una perspectiva cartográfica, no se trataría entonces sólo de describir, lo que surge como más significativo, sino que además de hacerlo, surge la posibilidad de analizar las relaciones entre los diferentes componentes que, en el proceso de puesta en escena de este instrumento de intervención, se muestran como relevantes. En el desarrollo de ese proceso, tal vez lo más significativo pase por el estudio de las relaciones entre los componentes que complementa la descripción de éstos. Es decir, trabajando desde el reconocimiento de la movilidad permanente de los elementos que componen aquello que se pretende conocer y transformar, tratando de comprender que las circunstancias sociales no son estáticas, están en permanente movimiento a través del propio devenir de la sociedad, la visión que se tiene sobre éstas y los cambios en la singularidad de los actores sociales que las definen. De esta manera se pueden visibilizar en forma sistemática y profunda, las diferentes formas de relación, unión, similitudes, diferencias e intensidades entre los distintos componentes heterogéneos que construyen, constituyeron y se presentan en perspectiva futura dentro de un espacio territorial (Testa, 2013).

Esta posibilidad de movimiento también puede ser pensada como una explicación o aproximación a las múltiples causalidades de las circunstancias que les dan forma, tendencias y sentido. Las Cartografías Sociales pensadas como una gramática, tienen posibilidades de aportar al conocimiento de la complejidad de los territorios de Intervención en lo Social y de generar, desde allí, una estructura con capacidad de organizar, desde diferentes ángulos, la complejidad de los escenarios sociales actuales y la puesta en escena de éstos desde la configuración, complejidad y perspectiva que le otorgan los actores que lo habitan. 
De este modo, los mapas, como producción colectiva, se inscriben como algo más que reflejos estáticos de una realidad. También son muestra de la expresión de un mundo construido desde lo social, lo cultural, lo simbólico, lo histórico y lo político, generando una forma diferente de acceso a lo territorial, pudiendo entender el territorio como una forma de historia que puede ser contada desde las palabras de quienes lo habitan. De este modo, el territorio es una fuente de conocimiento que da cuenta de las posibilidades de resolución de los problemas sociales, como así también, de las dificultades y circunstancias que los construyen, aportando una perspectiva situada (Tetamanti \& Escudero, 2012).

Las cartografías sociales, en tanto instrumentos de intervención poseen la capacidad de articular lo teórico y lo metodológico en un mismo procedimiento, fuertemente singular, potenciando, de alguna manera, las posibilidades de transformación desde las prácticas y generando nuevas formas de construcción de conocimiento. A su vez, las cartografías como dispositivos de intervención en lo social, construyen nuevos escenarios al aportar y reconstruir diferentes miradas y relatos territoriales, otorgando además, una mirada compleja y apropiable. Así, se presentan como una tarea que facilita la construcción colectiva de conocimiento, posibilitando, desde allí, la generación de diferentes acciones con capacidad de transformar escenarios, lugares y espacios diversos, incluso los institucionales.

Las Cartografías Sociales, en la medida que llevan adelante su capacidad de articular lo territorial con lo microsocial, mediante interrogantes que se construyen en el contexto, poseen la capacidad de trabajar en la construcción de subjetividad, haciendo visible aquello que el territorio - desde su lenguaje, disposición, ordenno deja ver. Las cartografías pueden ser asociadas a diferentes formas de reconocimiento, especialmente a través de lo visual, pero también desde el relato.

Contar la historia de un barrio y ubicar sus puntos sobresalientes desde lo territorial permite articular las diferentes formas del 
relato con lo percibido, donde las imágenes tienen la posibilidad de cobrar formas más relacionadas con las significaciones que les otorgan los propios actores sociales (Carballeda, 2013). Por otra parte, es posible pensar a las Cartografías Sociales como una búsqueda de estrategias e insumos de intervención, que intentan ir más allá de la observación y se relacionan con la forma de implicarse desde el hacer del Trabajo Social. Si se propone a la intervención como un proceso que tiene por horizonte una forma de mirada que intenta combinar e integrar en función de aquello que se describe, se hace mapa y elabora su propia topología, también es posible pensar en instrumentos de acción que faciliten la construcción de mediaciones que se relacionan con la comprensión y explicación de los motivos en los que se interviene.

Las Cartografías Sociales se convierten, de esta manera, en una opción metodológica y conceptual que se orienta a una construcción de conocimiento territorial, con la singularidad que en la medida que ese proceso se produce, genera transformaciones de diferente orden, al ser construcciones colectivas, que se realizan a través de diferentes representaciones gráficas producto de la conjunción entre el dato objetivo, la historia y los imaginarios sociales. Dentro del proceso de aplicación de éstas, también se utilizan otros procedimientos como la entrevista, la aplicación del dispositivo grupal mediante talleres, recuperación de narrativas que apuntan a un recorrido que va desde la integración entre lo simbólico, lo real y la propia vivencia situada en lo territorial.

\section{Bibliografía}

Carballeda, A. (2013). La intervención en lo social como proceso. Editorial Espacio, Buenos Aires.

Testa, M.C. (2013). Compiladora. Trabajo Social y Territorio. Reflexiones sobre lo público y las instituciones. Editorial Espacio. Buenos Aires.

Tetamanti, J.M., Escudero, H. (2012). Compiladores. Cartografía Social. Investigación e Intervención desde las Ciencias Sociales. Ministerio de Educación. Secretaría de Políticas Universitarias. Argentina. 
Vélez, I., Rátiva, S., Varela, D. (2012). Cartografía social como metodología participativa y colaborativa de investigación en el territorio afrodescendiente de la cuenca alta del río Cauca. Revista colombiana de geografía, $\mathrm{N}^{\circ} 2$, Vol. 21, pp. 59-73. 